\title{
KONVERSI LAMPU TL KE LAMPU LED ( STUDI KASUS : JAKABARING SHOOTING RANGE JAKABARING SPORT CITY PALEMBANG )
}

\author{
Nita Nurdiana ${ }^{1}$, M. Saleh Al Amin ${ }^{2}$, Abdurrahman Thohari ${ }^{3}$ \\ 1,2,3 Program Studi Teknik Elektro, Fakultas Teknik, Universitas PGRI Palembang \\ e-mail: nurdiana78@ univpgri-palembang.ac.id
}

\begin{abstract}
Abstrak - Dengan adanya momentum pergelaran kompetisi olahraga tingkat Asia yaitu Asian Games 2018 yang akan diadakan di Jakarta dan Palembang, Jakabaring Shooting Range Palembang melakukan renovasi pada gedungnya untuk menunjang suksesnya Asian Games 2018 pada cabang olahraga menembak. Renovasi ini juga menganti atau mengkonversikan lampu yang sebelumnya menggunakan lampu TL 2 × 36 Watt menjadi menggunakan lampu flat LED 40 Watt. Dalam hal ini bertujuan untuk mengetahui perbandingan ini adalah dengan menghitung secara teoritis kuat penerangan, daya yang dihasilkan serta biaya yang dikeluarkan. Dari hasil perbandingan didapatkan perbandingan secara terotirs bagaimana yang lebih baiknya dan melihat kedua lampu tersebut apakah memenuhi syarat standar penerangan pada ruang arena menembak Bahwa lampu LED memiliki kuat penerangan hampir sama dengan lampu TL tetapi dari segi daya listrik yang digunakan lampu LED menghasilkan daya listrik yang lebih kecil dengan daya listrik yang lebih kecil ini didapat tarif listrik yang murah pula, dengan begitu LED sangat bisa menjadi lampu yang hemat energi serta hemat pengeluaran uang.

Kata Kunci : Pencahayaan, Kuat Penerangan, Daya Listrik, Tarif Listrik
\end{abstract}

\begin{abstract}
Asian Games 2018 which will be held in Jakarta and Palembang, Jakabaring Shooting Range Palembang to renovate the building to support the success of Asian Games 2018 at shooting sport. This renovation also replace or convert lamps that previously used TL $2 \times 36$ Watt lamps to use 40 Watt LED flat lights. In this case the aim to know this comparison is by calculating theoretically strong illumination, the power generated as well as the cost incurred. From the comparison results obtained the comparison terotirs how the better and see the two lights are whether the standard qualified lighting in the arena shooting space That LED lights have a strong light almost the same as the TL lamps but in terms of electric power used LED lights generate more electrical power small with a smaller electric power is obtained electricity tariffs are also cheap, so LEDs can be very energy-efficient lamps and save money.
\end{abstract}

Keywords : Lighting, Lighting Power, Electrical Power, Electricity Tariff

\section{PENDAHULUAN}

Penerangan yang baik dan memadai memegang peranan penting dalam suatu gedung atau bangunan agar pekerjaan yang berlangsung di dalamnya dapat dijalankan secara efisien dan aman. Selain itu, penerangan yang cukup dan baik akan berguna pula untuk menciptakan suasana yang nyaman dan menyenangkan.

Penerangan pada Jakabaring Shooting Range dirancang agar para atlet penembak dalam melihat dengan jelas jarak sasaran. Posisi lampu juga tidak boleh menyilaukan mata atlet yang disebabkan oleh pantulan cahaya. Penerangan lampu pada arena olahraga menembak atau shooting range adalah dengan menggunakan jenis lampu Fluoresen $(\mathrm{TL}=$ tubelair lamp) dan untuk saat ini penerangan pada arena menembak akan dikonversikan ke jenis lampu LED (Light Emitting Diode).. 
Dengan begitu untuk menyelesaikan ini diperlukan konversi yang baik untuk menunjang kegiatan Asian Games 2018 di Jakabaring Sport City pada arena Shooting Range atau lapangan tembak, serta melakukan studi kasus bagaimana perbandingan antara sebelum konversi dan sesudah konversi.

Penelitian bertujuan memberikan sebuah hasil perbandingan dari konversi antara lampu TL maupun lampu LED, mulai dari perbandingan intensitas penerangan, kuat penerangan, daya lsitrik, sampai dengan tarif yang dikeluarkan. Jakabaring Shooting Range khusus range 10 meter sepenuhnya mengandalkan pencahayaan buatan, siang hari pun lampu dianggap menyala total. Penelitian ditujukan pada pencahayaan buatan, pengaruh cahaya matahari tidak diperhitungkan. Penelitian dilakukan dengan tidak mengubah sedikitpun antara jarak plafon ke lantai dan bentuk ruangan, hanya saja perenovasian ini diprioritaskan hanya mengubah dari sistem instalasi listrik dan penggunaan lampu saja. Pada awal pembangunan menggunakan lampu TL dan tahap renovasi mengubah lampu LED.

\section{TINJAUAN PUSTAKA}

Penelitian terkait Lampu LED telah dilakukan oleh Puji dan Gatut (2016), menghasilan nilai perbandingan intensitas pencahayaan, pemakaian daya, dan pemakaian energi dalam kurun waktu yang sama dan didapatkan bahwa nilai pengukuran pada lampu LED menunjukkan nilai positif dalam sesi dibandingan dengan lampu TL [6]. Dalam tulisan Iskandar,Abdullah dan Agus (2015), lampu LED dapat dijadikan lampu masa depan, karena lampu LED memiliki cahaya yang terang, warna yang bagus serta hemat energi, dan bisa dibawa dengan mudah [2]. Dan menurut Wahyudin (2012) penerangan menggunakan lampu LED dapat menghemat penggunaan energi listrik hingga $70 \%$ [8], menghemat biaya penagihan listrik untuk penerangan, dengan lifetime yang mencapai 50.000 jam atau sekitar 8 tahun kita dapat menghemat biaya pergantian lampu baru yang rata-rata bertahan 2 tahun saja. Dan dari segi untuk lingkungan jenis lampu LED merupakan lampu yang ramah lingkungan karena tidak mengandung unsur merkuri serta tidak merusak lingkungan sekitar karena tidak ada UV-dari pancaran sinarnya.

\section{Lampu TL [4,5]}

Lampu fluoresen $(\mathrm{TL}=$ tubelair lamp) termasuk lampu merkuri tekanan rendah $(0,4 \mathrm{~Pa})$ yang dilengkapi dengan bahan fluoresen. Cahaya yang dipancarkan dari dalam lampu dalah ultraviolet (termasuk sinar tak tampak). Untuk itu bagian dalam lampu tabung dilapisi bahan fluoresen yang fungsinya mengubah ultraviolet menjadi sinar tampak. Pada desain pencahayaan 
ruang, lampu fluoresens banyak digunakan untuk menghasilkan cahaya yang merata untuk memenuhi kebutuhan fungsional berbagai aktivitas. Cahaya putih jernih yang merata yang dihasilkan dengan kecenderungan untuk tidak mempengaruhi warna benda, membuat lampu fluoresens mampu menampilkan objek visual dengan sangat baik.

\section{Lampu LED [3,5]}

Lampu LED adalah produk diode pancaran cahaya (LED) yang disusun menjadi sebuah lampu. Lampu LED memiliki usia pakai dan efisiensi listrik beberapa kali lipat lebih balik daripada lampu pijar dan tetap jauh lebih efisien daripada lampu neon. Lampu LED hanya butuh energi sebesar $10 \%$ dari energi yang dibutuhkan lampu pijar. Perkembangan teknologi lampu yang pesat telah mengantar penciptaan jenis lampu baru, yaitu LED (Light Emmiting Diode). Lampu LED memiliki usia yang sangat panjang, dengan konsumsi daya listrik yang sangat kecil. Lampu LED sangat menunjang desain pencahayaan karena memiliki variasi warna, yaitu putih dingin (cool white), kekuningan, merah, hijau, dan biru. Variasi warna ini memungkinkan penciptaan suasana ruang maupun objek yang senantiasa berubah (color changing) dengan memainkan warna-warna yang berbeda pada waktu-waktu tertentu.

\section{Pemahaman Lapangan Tembak [1,7]}

Untuk tingkat penerangan, pencegahan silau serta sumber cahaya lampu harus memenuhi ketentuan sebagai berikut :

Tabel 1 Persyaratan Penerangan dalam Ruangan Menembak

\begin{tabular}{|l|c|c|c|}
\hline \multirow{2}{*}{$\begin{array}{c}\text { Tipe Ruang } \\
\text { Indoor }\end{array}$} & $\begin{array}{c}\text { Rekomendasi Besaran } \\
\text { Kuat Pencahayaan } \\
\text { (Minimum) }\end{array}$ & \multicolumn{2}{|c|}{ Pencahayaan Target } \\
\cline { 3 - 4 } & 500 & 1500 & Rekomendasi \\
\hline $10 \mathrm{~m}$ & 500 & 1000 & $>1800$ \\
\hline $10 \mathrm{~m}$ RT & 500 & 1500 & $>2500$ \\
\hline $25 \mathrm{~m}$ & 500 & 1500 & $>3000$ \\
\hline $50 \mathrm{~m}$ & & & \\
\hline
\end{tabular}

1. Tingkat penerangan horizontal pada arena $1 \mathrm{~m}$ diatas permukaan lantai untuk ke-3 kelas, sebesar :

- Untuk latihan dibutuhkan minimal 200 lux;

- Untuk pertandingan dibutuhkan minimal 500 lux;

- Untuk pengambilan video dokumentasi dibutuhkan minimal 1000 lux

2. Semua range dalam ruangan harus memiliki iluminasi buatan yang menyediakan jumlah cahaya yang diperlukan tanpa silau atau bayangan yang mengganggu pada sasaran atau titik tembak. 
3. Sumber cahaya lampu atau bukan harus diletakan dalam satu area pada langit-langit sedemikian rupa

4. Masing-masing tata lampu harus merupakan instalasi yang terpisah, satu dengan lainnya

5. Apabila menggunakan tata cahaya buatan, harus disediakan generator set yang kapasitas dayanya minimum $60 \%$ dari daya terpasang, generator set harus dapat bekerja maksimum 10 detik pada saat setelah aliran PLN padam.

\section{Dasar Sistem Penerangan [3]}

a. Intensitas Cahaya

Intensitas cahaya (I) dengan satuan kandela (cd) adalah arus cahaya dalam lumen yang diemisikan setiap sudut ruang (pada arah tertentu) oleh sebuah sumber cahaya. (Muhaimin, 2001). Intensitas cahaya (I) dapat dinyatakan sebagai perbandingan diferensial arus cahaya (lm) dengan difernsial sudut ruang (sr).

$$
\mathrm{I}=\text { Lumen } \mathrm{x} \text { Luas lampu } \mathrm{x} \cos \alpha
$$

b. Kuat Penerangan (Iluminasi)

Iluminasi (E) adalah cahaya yang jatuh pada sebuah permukaan. Hal ini diukur terhadap fluksi penerangan yang diterima pada luas satuan, misalnya lumen setiap $\mathrm{m}^{2}$. (Michel Neidle, 1989). Satuannya adalah LUX. Dengan menggap sumber penerangan sebagai titik yang jaraknya (h) dari bidang penerangan maka iluminasi (E) dalam lux (lx) pada suatu titik pada bidang penerangan adalah:

$$
\mathrm{E}=\frac{\mathrm{I}}{\mathrm{h}^{2}} \operatorname{lux}
$$

Persamaan (2) lazim disebut Hukum Kuadrat Terbalik (Inverse Square Law).

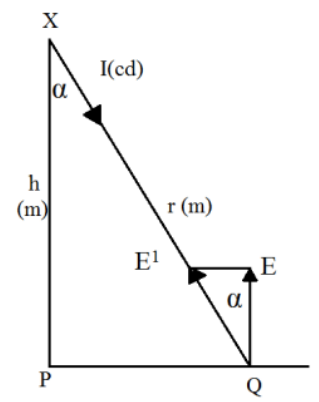

\section{Gambar 2. Hukum Kuadrat Terbalik}

$\mathrm{E}^{1}$ adalah kuat penerangan pada bidang yang tegak lurus $\mathrm{PQ}$, sesuai dengan hukum kuadrat terbalik, $\mathrm{E}^{1}=\frac{\mathrm{I}}{\mathrm{r}^{2}}$ Kuat penerangan pada bidang horizontal (melalui garis PQ) adalah E:

$$
\mathrm{E}=\frac{\mathrm{I}}{\mathrm{h}^{2}} \cdot \cos \alpha \mathrm{lx}
$$


c. Luminasi

Luminansi (L) merupakan besaran penerangan yang erat kaitannya dengan kuat penerangan (E). Luminansi adalah pernyataan kuantitatif jumlah cahaya yang dipantulkan oleh permukaan pada suatu arah. Luminansi suatu permukaan ditentukan oleh kuat penerangan dan kemampuan memantulkan cahaya oleh permukaan. (Muhaimin, 2001)

$$
\mathrm{E}=\frac{4 \cdot \pi \cdot 1}{4 \cdot \pi \cdot 3,28^{2}}
$$

d. Suhu Warna

Untuk suhu warna ini adalah mengetahui besaran suhu yang dikeluarkan lampu pada saat menyala atau digunakan. Suhu berpengaruh terhadap kenyamanan pengunjung atau orangorang yang didalam ruangan. [5]

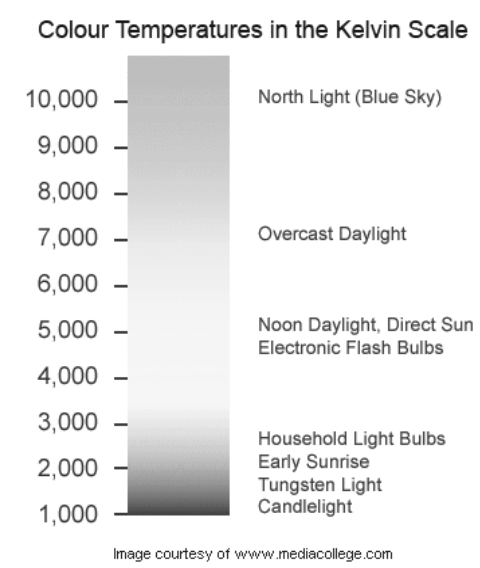

Gambar 4 Skala Suhu Warna Lampu

e. Usaha dan Daya Listrik

Usaha listrik adalah sebuah tegangan yang diberi arus untuk waktu yang ditentukan. Sedangkan daya adalah hasil dari usaha dibagi waktu.

$$
\mathrm{W}=\mathrm{E} \times \frac{\mathrm{E}}{\mathrm{R}} \times \mathrm{t}=\frac{\mathrm{E}^{2}}{\mathrm{R}} \mathrm{t}
$$

Untuk menghitung besarnya daya yang dihasilkan maka untuk menghitungnya dengan mengunakan perhitungan sebagai berikut:

$$
P=E \times \frac{E}{R}=\frac{E^{2}}{R}
$$

f. Perhitungan Biaya

Untuk menghitung Tarif pengunaan listrik bisa dihitung dengan:

$$
\text { Tarif }=\text { Pemakaian listik atau Daya }(\mathrm{KW}) \mathrm{x} \text { harga satuan (hours) }
$$




\section{METODE PENELITIAN}

Metode penelitian adalah cara atau jalan yang ditempuh dalam melaksanakan penelitian. Oleh karena itu penggunaan metode yang tepat sangat penting agar penelitian yang dilaksanakan dapat dipertanggung jawabkan kebenarannya. Lokasi penelitian ini adalah gedung olahraga pada komplek Jakabaring Sport City Palembang. Gedung tersebut adalah gedung Jakabaring Shooting Range, Palembang, dan untuk penelitiannya pada ruang menembak 10 meter atau ruang Range 10 Meter. Waktu penelitian dilaksanakan pada saat Jakabaring Shooting Range sedang melakukan renovasi.

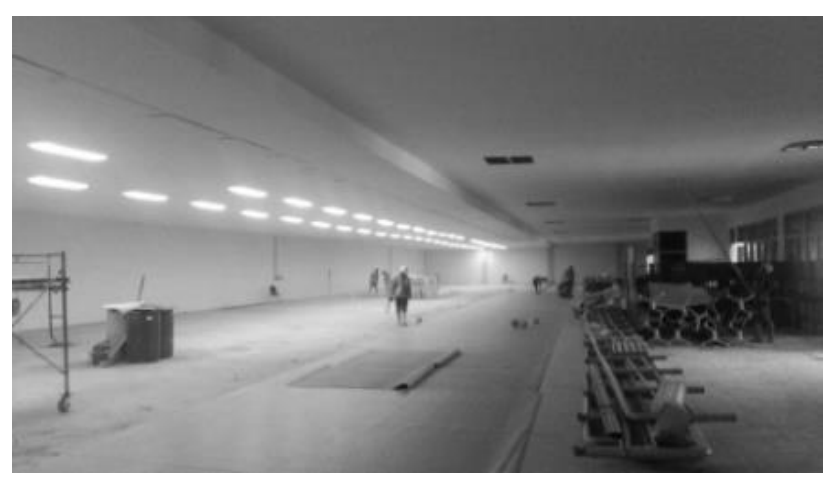

Gambar 3 Ruang Range 10 Meter

\section{HASIL DAN PEMBAHASAN}

Pada ruang Shooting Range 10 meter terletak di lantai 2 gedung Jakabaring Shooting Range.

Tabel 2 Data Ruang Shooting Range 10 Meter Jakabaring Shooting Range Palembang

\begin{tabular}{|c|c|c|}
\hline No. & Nama Data Ruangan & Hasil Data Ruangan \\
\hline 1. & Panjang Ruangan & 65 meter \\
\hline 2. & Lebar Ruangan & 16 meter \\
\hline 3. & Tinggi Ruangan & 4,2 meter \\
\hline \multirow{3}{*}{4.} & Jenis Lampu: & \\
\hline & Sebelum Direnovasi & Lampu TL (2x36 Watt) \\
\hline & Sesudah Direnovasi & Lampu Panel LED (40 Watt) \\
\hline \multirow{3}{*}{5.} & Ф Lampu: & \\
\hline & Sebelum Direnovasi & Lampu TL 36 Watt = 2500 lumen \\
\hline & Sesudah Direnovasi & Lampu LED 40 Watt = 3200 lumen \\
\hline \multirow{3}{*}{6.} & Banyaknya Lampu: & \\
\hline & Sebelum Direnovasi & 151 Titik Lampu \\
\hline & Sesudah Direnovasi & 151 Titik Lampu \\
\hline
\end{tabular}

\section{Sistem Penerangan Ruangan Shooting Range 10 Meter}

Pada ruangan menembak Shooting Range 10 meter terletak pada sisi barat dari pintu masuk gedung utama dan terletak dilantai 2 gedung Jakabaring Shooting Range Palembang. Sistem penerangan ruangan Shooting Range 10 meter diasumsikan mengunakan penerangan 
secara langsung dari penerangan buatan (Lampu). Penggambaran tata ruang dan tata letak sumber penerangan ruang menembak Shooting Range 10 meter gedung Jakabaring Shooting Range Palembang dapat dilihat pada gambar-gambar berikut.

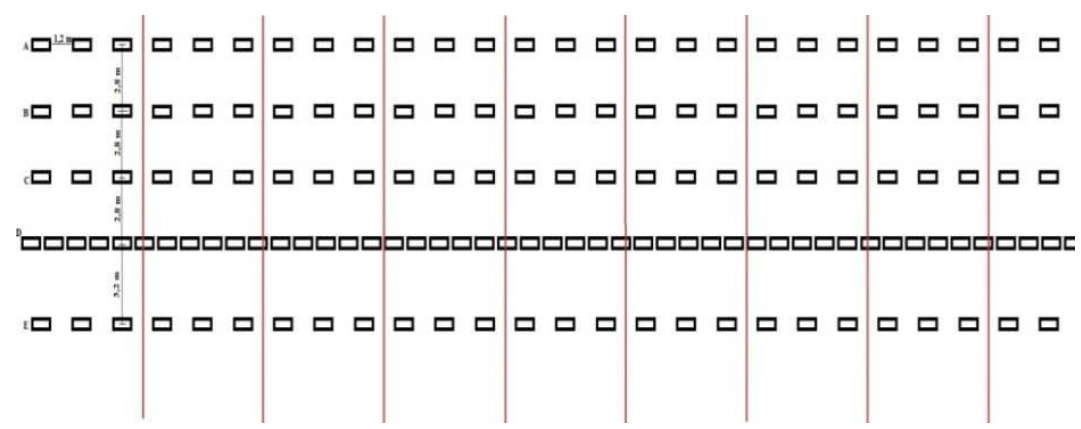

Gambar 2. Titik Armatur Lampu di Range 10 meter Jakabaring Shooting Range

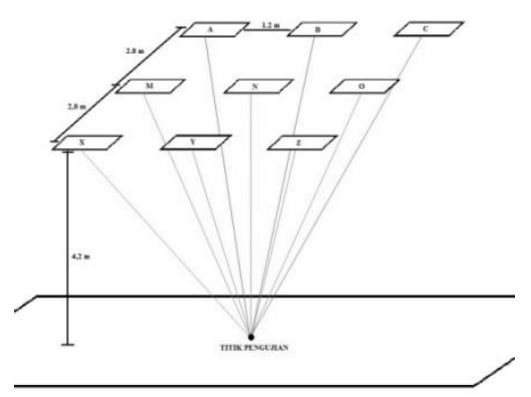

Gambar 4. Titik Pengujian Pada Area Sasaran
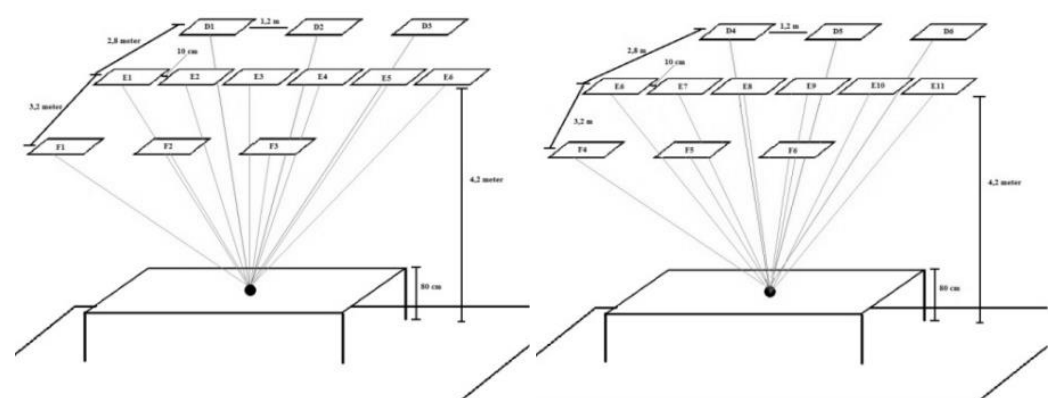

Gambar 5. Titik Pengujian Pada Area Menembak

Tabel 3. Hasil Perhitungan Intensitas dan Kuat Penerangan dengan Lampu TL

\begin{tabular}{|c|c|c|c|c|}
\hline \multirow{2}{*}{ Titik } & \multicolumn{2}{|c|}{ Area Sasaran Menembak } & \multicolumn{2}{c|}{ Area Start Menembak } \\
\cline { 2 - 5 } & $\begin{array}{c}\text { Intensitas } \\
\text { Cahaya }\end{array}$ & $\begin{array}{c}\text { Kuat } \\
\text { Penerangan }\end{array}$ & $\begin{array}{c}\text { Intensitas } \\
\text { Cahaya }\end{array}$ & $\begin{array}{c}\text { Kuat } \\
\text { Penerangan }\end{array}$ \\
\hline 1 & 9164,69 & 333,00 & 11626,24 & 601,42 \\
\hline 2 & 9164,69 & 333,00 & 11693,99 & 612,73 \\
\hline 3 & 9164,69 & 333,00 & 11626,24 & 601,42 \\
\hline 4 & 9164,69 & 333,00 & 11693,99 & 612,73 \\
\hline
\end{tabular}




\begin{tabular}{|c|c|c|c|c|}
\hline 5 & 9164,69 & 333,00 & 11626,24 & 601,42 \\
\hline 6 & 9164,69 & 333,00 & 11693,99 & 612,73 \\
\hline 7 & 9164,69 & 333,00 & 11626,24 & 601,42 \\
\hline 8 & 9164,69 & 333,00 & 11693,99 & 612,73 \\
\hline Rata-Rata & $\mathbf{9 1 6 4 , 6 9}$ & $\mathbf{3 3 3 , 0 0}$ & $\mathbf{1 1 6 6 0 . 1 2}$ & $\mathbf{6 0 7 , 0 8}$ \\
\hline
\end{tabular}

Tabel 4. Hasil Perhitungan Intensitas dan Kuat Penerangan dengan Lampu LED

\begin{tabular}{|c|c|c|c|c|}
\hline \multirow{2}{*}{ Titik } & \multicolumn{2}{|c|}{ Area Sasaran Menembak } & \multicolumn{2}{c|}{ Area Start Menembak } \\
\cline { 2 - 5 } & $\begin{array}{c}\text { Intensitas } \\
\text { Cahaya }\end{array}$ & $\begin{array}{c}\text { Kuat } \\
\text { Penerangan }\end{array}$ & $\begin{array}{c}\text { Intensitas } \\
\text { Cahaya }\end{array}$ & $\begin{array}{c}\text { Kuat } \\
\text { Penerangan }\end{array}$ \\
\hline 1 & 8798,1 & 319,68 & 11161,19 & 577,36 \\
\hline 2 & 8798,1 & 319,68 & 11226,23 & 588,22 \\
\hline 3 & 8798,1 & 319,68 & 11161,19 & 577,36 \\
\hline 4 & 8798,1 & 319,68 & 11226,23 & 588,22 \\
\hline 5 & 8798,1 & 319,68 & 11161,19 & 577,36 \\
\hline 6 & 8798,1 & 319,68 & 11226,23 & 588,22 \\
\hline 7 & 8798,1 & 319,68 & 11161,19 & 577,36 \\
\hline 8 & 8798,1 & 319,68 & 11226,23 & 588,22 \\
\hline Rata-Rata & $\mathbf{8 7 9 8 , 1}$ & $\mathbf{3 1 9 , 6 8}$ & $\mathbf{1 1 1 9 3 , 7 1}$ & $\mathbf{5 8 2 , 7 9}$ \\
\hline
\end{tabular}

Tabel 5. Hasil Perbandingan Lampu TL 2 x 36 Watt dan Lampu LED 40 Watt

\begin{tabular}{|l|c|c|}
\hline & Lampu & Lampu Flat \\
TL 2 x 36 & LED 40 Watt \\
\hline Intensitas Cahaya Tempat Area Sasaran (lumen) & 9164,69 & 8798,1 \\
\hline Intensitas Cahaya Tempat Area Start (lumen) & 11660.12 & 11193,71 \\
\hline Kuat Penerangan Tempat Area Sasaran (lx) & 333,00 & 319,68 \\
\hline Kuat Penerangan Tempat Area Start (lux) & 607,08 & 582,79 \\
\hline Daya Listrik (Watt) & 10962,6 & 5979,6 \\
\hline Suhu Warna (Kelvin) & 5800 & 5800 \\
\hline $\begin{array}{l}\text { Tarif Listrik yang dikeluarkan } \\
\text { (12 jam pemakaian) }\end{array}$ & Rp. 193.022,- & Rp. $105.285,-$ \\
\hline Lamanya waktu lampu menyala (Lifetime) (jam) & 10000 & 15000 \\
\hline
\end{tabular}

Untuk hasil intensitas lampu TL (flueresen) memiliki intensitas yang lebih besar dari intensitas cahaya lampu LED, sama juga dengan halnya dengan iluminasi cahaya Lampu TL (flueresen) memiliki iluminasi atau kuat penerangan yang besar. Karena lampu TL memiliki cahaya yang putih terang, sedangkan lampu LED memiliki cahaya yang dipancarkan berwarna putih kebiruan. Untuk keduanya, lampu TL dan LED sudah memenuhi standar internasional untuk iluminasi. Standar ilumunasi pada area menembak gedung olahraga menembak yang dipakai untuk pertandingan internasional sebesar $500 \mathrm{~lx}$ dan hasil perhitungan menunjukan hasil untuk pengunaan lampu TL menghasilkan kuat penerangan atau iluminasi sebesar 607,08 
lux sedangkan untuk pengunaan lampu LED menghasilakn iluminasi sebesar 559,70 lux maka dari itu menandakan bahwa sesuai standar internasional untuk iluminasi.

Dari hasil perbandingan diatas disimpulkan bahwa Lampu TL dan LED memiliki kelebihan dan kekurangn tersendiri yaitu untuk titik kesilauan lampu TL memiliki kesilauan yang sangat terang sedangkan lampu LED memiliki cahaya yang terang tapi tidak menyilaukan karena dari hasil perhitungan iluminasi dan pengamatan LED sangat aman untuk mata dan tidak membuat mata perih walau cahayanya terang. Dan untuk pengunaan listrik lampu LED lebih ringan dari lampu TL karena lampu LED menghasilkan daya listrik yang kecil dan lampu TL menghasilkan daya listrik yang besar sehingga menghasilkan tarif listrik yang mahal pula dan suhu pun juga berpengaruh karena suhu warna yang dihasilkan oleh lampu TL kecil dan membuat silau mata dan membuat suhu ruangan menjadi cepat hangat sedangkan lampu LED mengeluarkan suhu warna yang tidak begitu terang dan bisa mengurangi pengunaan pengdingin ruangan dan pengurangan daya listrik karena pendingin ruangan yang yang sedikit. Serta juga bisa menghemat pengeluaran keuangan untuk pembayaran tarif listrik.

\section{KESIMPULAN}

1. Dari hasil perhitungan iluminasi pada arena start menembak menunjukan bahwa kuat pencahayaan sebelum renovasi menggunakan lampu TL 2 x 36 Watt sebesar 607,08 lux sedangkan hasil perhitungan kuat pencahayaan setelah dilakukan renovasi dengan mengkonversi ke lampu LED 40 Watt menghasilkan besaran sebesar 582,79 lux yang berarti kedua penggunaan lampu tersebut telah sesuai dengan standar yang telah ditetapkan oleh ISSF (International Shooting Sport Federation) minimal sebesar 500 lux.

2. Dari hasil perbandingan pada tabel 4.6 menunjukan perbandingan pada kuat cahaya tidaklah begitu jauh tetapi pada perbandingan daya listrik yang dihasilkan untuk lampu TL 2 x 36 watt didapat hasil sebesar 10962,6 watt sedangkan untuk lampu LED 40 watt didapat hasil sebesar 5979,6 watt. Maka dari itu lampu LED sangatlah ramah lingkungan dikarenakan bisa menghemat listrik karena menghasilkan daya listrik yang sangat kecil dibandingkan daya listrik lampu TL.

3. Untuk lamanya ketahanan yang sesuai standar dalam hal intensitas cahaya dan kuat penerangan lampu LED memliki waktu yang sangat lama dalam hal menyala selama 15.000 jam dibandingkan lampu TL yang hanya 10.000 jam saja.

\section{DAFTAR PUSTAKA}


1. Anomim, "Pemahaman Terhadap Pusat Pelatihan dan Sarana Olahraga Menembak" (http://erepo.unud.ac.id/9245/3/8dfb295a85b339657952d64f9ad0c4d6.pdf) diakses 15 November 2017

2. Iskandar, Abdullah, Suharijanto, Agus Supriyadi. 2015. Evaluasi Pengunaan Lampu LED Sebagai pengganti Lampu Konvensional, No. ISSN 2502-0986, (http://journal.unisla.ac.id/pdf/110122016/jurnal4.pdf diakses 15 November 2017).

3. Linsley, Trevor. 2004. Instalasi Listrik Tingkat Lanjut. Terjemahan oleh: Wiwit Kastawan. Erlangga, Jakarta, Indonesia.

4. Muhaimin. 2001. Teknologi Pencahayaan. Refika Aditama, Bandung, Indonesia.

5. Neidle, Michael. 1999. Teknologi Instalasi Listrik. Terjemahan oleh: Ir. Sahat Pakpahan. Erlangga, Jakarta, Indonesia.

6. Puji Slamet1, Gatut Budiono, 2016, Kajian Teknis Lampu LED Type Tabung Dibandingkan dngan Lampu TL, JHP17 Jurnal Hasil Penelitian LPPM Untag Surabaya, Vol. 01, No. 01, hal 53 - 60

7. Standar SNI 03-3647-1994 tahun 1994 tentang Tata Cara Perencanaan Teknik Bangunan Gedung Olahraga. 1995. Bandung: Departemen Pekerjaan Umum Diperbanyak oleh Yayasan LPMB.

8. Wahyudin. 2012. Analisa Efisiensi Pemakaian Listrik dengan Lampu LED Untuk Penerangan Depot LPG Tg. Priok, Pertamina Learning Center (PLC), Jakarta, Indonesia. (http://yotomoproduction.blob.core.windows.net/apaidemu/d88c152e-1515-4184-8fa4c18043a1abb6.pdf) diakses 17 November 2017. 